\title{
CRIAÇÃO DE PACAS (Cuniculus paca) COMO ALTERNATIVA DE DIVERSIFICAÇÃO DE PRODUÇÃO E RENDA EM RIO BRANCO - ACRE
}

\author{
Francisco Cildomar da Silva Correia \\ Reginaldo da Silva Francisco ${ }^{1}$ \\ Valderi Tananta de Souza ${ }^{1}$ \\ Vania Maria Franca Ribeiro ${ }^{1}$ \\ Fábio Augusto Gomes ${ }^{1}$
}

CORREIA, F. C. S.; FRANCISCO, R. S.; SOUZA, V.; RIBEIRO, V. M. F.; GOMES, F. A. Criação de pacas (Cuniculus paca) como alternativa de diversificação de produção e renda em Rio Branco - Acre. Arq. Ciênc. Vet. Zool. UNIPAR, Umuarama, v. 19, n. 2, p. 81-89, abr./jun. 2016.

\begin{abstract}
RESUMO: Para iniciar uma atividade comercial, estudos neste segmento devem ser realizados para verificação da viabilidade econômica e financeira, analisando as oportunidades e os riscos pertinentes ao projeto. Dessa forma, a finalidade deste estudo foi analisar indicadores de viabilidade de custo-benefício dos investimentos para um projeto de criação comercial de pacas (Cuniculus paca), em Rio Branco-Acre. Para este estudo utilizou-se índices econômicos para criação de 36 matrizes e 12 reprodutores, sendo um macho para três fêmeas, em sistema intensivo de produção, considerando-se a construção do galpão com o uso de parte da matéria-prima disponível na região, mão de obra local de profissionais autônomos, assistência técnica fornecida por órgãos públicos, alimentação adquirida na propriedade, animais fornecidos pelo IBAMA, por meio de doações e/ou capturados, mão de obra familiar para criação dos animais, custo de produção dos animais, valor da carne vendida para restaurantes $\mathrm{R} \$ 35,00 / \mathrm{Kg}$, preço do prato individual comercializado pelos restaurantes, porção de $250 \mathrm{~g} R \$ 30,00 / 40,00$ e 50,00, dependendo do restaurante. Os resultados destacaram como principais custos para a implantação da atividade, a construção das instalações, considerando-se matéria-prima e mão de obra. Além disso, constatou-se que a criação comercial de pacas pode se tornar uma alternativa viável da diversificação de produção e renda para produtores da região.
\end{abstract}

PALAVRAS-CHAVE: Criação comercial de pacas.Sistema intensivo de produção.Viabilidade econômica.

\section{PACAS CREATION (Cuniculus paca) AS PRODUCTION DIVERSIFICATION OF ALTERNATIVE AND INCOME IN RIO BRANCO - ACRE}

\begin{abstract}
For feasibility and performance of commercial activity, we need to study for economic and financial evaluation, verification of the opportunities and risks relevant to the project. Therefore, the purpose of this study was to analyze the investment cost-benefit feasibility indicators for a commercial breeding project pacas (Cuniculus paca) in Rio Branco-Acre. For this study we used economic indices for creating arrays 36 and 12 breeders, with a male to female three in intensive production system, considering the construction of the shed with the use of the available raw material in the region hand local work of independent professionals, technical assistance provided by public agencies, gained power in the property, animals supplied by IBAMA through donations and / or captured, family labor for animal husbandry, production cost of animals, the value of meat to Restaurants will be $\mathrm{R} \$ 35.00 \mathrm{~kg}$, the price of individual plate to be sold by restaurants, $250 \mathrm{~g}$ portion of $\mathrm{R} \$ 30.00 / 40.00$ and 50.00, that depending on the restaurant. The results highlighted as major costs for the implementation of activity the construction of the facility, considering raw materials and labor. The results of this study found that trade creation of pacas can become a viable alternative to diversify production and income for producers in the region.
\end{abstract}

KEYWORDS: Commercial breeding of pacas. System intensive production. Economic viability.

\section{CREACIÓN DE PACAS (Cuniculus paca) COMO ALTERNATIVA DE DIVERSIFICACIÓN DE PRODUCCIÓN Y GANANCIA EN RIO BRANCO - ACRE}

RESUMEN: Para la viabilidad y el desempeño de una actividad comercial hay necesidad de estudios de evaluación económica y financiera, la verificación de las oportunidades y los riesgos pertinentes para el proyecto. Por lo tanto, el propósito de este estudio ha sido analizar los indicadores de viabilidad de coste/beneficio de las inversiones para un proyecto de creación comercial de pacas (Cuniculus paca) en Rio Branco-Acre. Para este estudio se utilizó los indicadores económicos para la creación de 36 matrices y 12 reproductores, siendo un macho para tres hembras, en sistema intensivo de producción, considerándose la construcción del galpón con la utilización de una parte de las materias primas disponibles en la región, la mano de obra local de profesionales autónomos, asistencia técnica proporcionada por organismos públicos, alimentación adquirida en la propiedad, animales proporcionados por IBAMA, a través de donaciones y/o capturados, mano de obra familiar para la ganadería, costo de producción de los animales, valor de la carne vendida a los restaurantes de $\mathrm{R} \$ 35,00 / \mathrm{kg}$, el precio del plato individual vendido por restaurantes, porción de 250 g de $\mathrm{R} \$ 30.00 / 40.00$ y 50.00, dependiendo del restaurante.

DOI: https://doi.org/10.25110/arqvet.v19i2.2016.5925

${ }^{1}$ Centro de Ciências Biológicas e da Natureza, Universidade Federal do Acre - UFAC, Rod. BR 364, Km 4, Distrito Industrial, CEP: 69.920-900, Rio Branco, Acre, Brasil. (cildomar12@hotmail.com). 
Los resultados destacaron como principales costos, para la implantación de la actividad, la construcción de las instalaciones, considerándose materias primas y mano de obra. Además, se encontró que la creación comercial de pacas puede convertirse en una alternativa viable de diversificación de producción y renta para los productores de la región.

PALABRAS CLAVE: Creación comercial de pacas. Sistema intensivo de producción. Viabilidad económica.

\section{Introdução}

Existem apenas um gênero e duas espécies de pacas, que são: Cuniculus paca e Cuniculus taczanowiskii [Linnaeus1766]. Essas duas espécies habitam lugares distintos (PÉREZ, 1992; MOREIRA; MACDONALD1997; NOGUEIRA FILHO; NOGUEIRA, 1999). Sendo C. taczanowiskii, encontrada apenas na região andina e $C$. paca, em uma grande variedade de habitats na América do Sul, que vai desde a Bacia do Rio Orinoco até o Paraguai.A paca é um animal de hábitos noturnos e que, geralmente, vive próximo de lagos, rios ou riachos, em florestas tropicais úmidas (ZUCARATTO; CARRARA; FRANCO, 2010).

C. paca e C. taczanowiskii, pertencem a ordem Rodentiae e família Cuniculidae. A espécie C. paca é considerada o segundo maior roedor encontrado no Brasil, sendo o primeiro a capivara (Hydrochoerus hydrochaeris) (PEREIRA; NORONHA; VARGAS, 2014).

A paca encontra-se entre as espécies em processo de extinção local, segundo a União Internacional de Conservação da Natureza - IUCN - (STRADIOTTI et al., 2007). A criação de pacas e de outros animais silvestres da fauna brasileira tem sido considerada, nas últimas décadas, uma alternativa usual para conservação de áreas de florestas nativas e a diminuição da caça predatória (LOURENCO; DIAS; GOMES, 2008). Além disso, possibilita a diversificação de produção e de renda para produtores rurais de diferentes regiões do país.

O Instituto Brasileiro do Meio Ambiente e dos Recursos Naturais Renováveis criou a Portaria IBAMA $\mathrm{n}^{\circ}$ 117/97, que trata sobre a comercialização da paca. Nessa mesma portaria, o Art. $7^{\circ}$ estabelece que o criadouro de animais da fauna silvestre brasileira com fins comerciais, devidamente registrados pelo IBAMA, poderá comercializar somente animais, produtos e derivados provenientes de reprodução, recria ou manejo em cativeiro (IBAMA, 1997). Atualmente, a criação e comercialização de produtos e subprodutos da fauna silvestre brasileira é regulamentada pela Instrução Normativa IBAMA 169, de 20 de fevereiro de 2008.

A criação de pacas, na forma de agricultura familiar, pode ser importante economicamente, considerando-se que já existe, por parte da população amazônica, o hábito de consumir carne de animais silvestres e, por esse motivo, há um mercado promissor para carnes exóticas. A carne de paca é uma rica fonte de proteína animal, além disso, seu couro possui elevada demanda no mercado internacional (LUI; NETO, 2008).

$\mathrm{Na}$ tentativa de reduzir a caça predatória, tem-se buscado a criação de pacas em cativeiro, principalmente na forma de manejo intensivo. Essa atividade representa uma alternativa de conservação, no que tange ao aumento de sua reserva populacional, diminuição da caça e do tráfico, além de contribuir para a conservação das áreas marginais às florestas ou às reservas.

Segundo Campo-Rozo e Ulloa (2003), para fortalecer o consumo de proteína animal na Amazônia, propõe-se a criação em cativeiro como um sistema de uso racional das espécies da fauna silvestre, que é uma proposta admissível para as espécies mais consumidas pela comunidade da região, pois a criação de animais silvestres tem sido apontada como uma possível fonte de proteína animal para populações mais pobres do interior de países em desenvolvimento, como o Brasil (NOGUEIRA FILHO; NOGUEIRA, 2000).

Para a criação de pacas em cativeiro, costuma-se adotar o sistema de convivência de três a cinco fêmeas para um macho em baias de $12 \mathrm{~m}^{2}$ (HOSKEN; SILVEIRA, 2001; RIBEIRO; ZAMORA, 2008), pois as gerações de pacas nascidas em cativeiro tendem a tornar-se sociáveis e dóceis (SMYTHE, 1991; HOSKEN, 1998).

Dessa forma, o presente trabalho teve como objetivo analisar a viabilidade econômica da implantação da criação comercial de pacas em Rio Branco - Acre, e determinar indicadores de custo-benefício dos investimentos.

\section{Material e Métodos}

$\mathrm{O}$ estudo de viabilidade econômica e financeira foi elaborado a partir de pesquisa de mercado, por meio do levantamento de preços da matéria-prima necessária para construção do galpão de manejo, nas principais lojas de material de construção, lojas de ferragens e madeireiras, em Rio Branco, Acre, no mês de junho de 2015. Obtiveram-se também preços de mão de obra local de carpinteiros e pedreiros para construção do galpão, utilizando-se profissionais liberais (autônomos). Também foi efetuada pesquisa acerca dos valores que os restaurantes estão dispostos a pagar pelo quilo da carne e o preço a ser repassado ao consumidor final, ou seja, o valor praticado pelos restaurantes por uma porção individual de $250 \mathrm{~g}$ de carne de paca, como também o lucro obtido pelo produtor.

A pesquisa de preço considerou a construção de um galpão para criação de 48 animais, sendo 36 matrizes e 12 reprodutores, levando em consideração a receita estimada com a venda dos animais, tendo como base o peso médio por carcaça de $6 \mathrm{Kg}$ /animal a U\$\$11,32/Kg e o número de animais comercializados/ano.

A consulta de valores referentes a algumas das matérias-primas foi realizada em três estabelecimentos diferentes, considerando-se material de construção e ferragens, três profissionais autônomos (pedreiros e carpinteiros), três operadores de motosserra, para extração de madeira disponível na propriedade para construção do galpão e três estabelecimentos comerciais, especializados na venda de alimentos (restaurantes).

Além da estrutura física necessária para criação das pacas, que é representada pelo galpão, o manejo desses animais utiliza outros equipamentos, como: brincos de identificação, comedouros e bebedouros produzidos a partir de material reciclado (pneus), EPI (avental de polietileno, botas com biqueira plástica e luvas de borracha), produtos de limpeza (detergente limpador e cal para pintura) e equipamentos (pá, vassoura, mangueira, balde, facão e enxada), necessários 
para higienização do criatório, que é feita pelos próprios criadores; bem como atenção com a saúde dos animais, por meio de assistência técnica especializada,fornecida por órgãos governamentais, o que não acarreta gastos para o produtor.

Para avaliar a viabilidade de investimento em um criatório comercial de pacas, foram realizadas algumas análises e calculados indicadores nesse sentido. De acordo com Miranda et al.(2010), com adaptações, dentre os indicadores, podem-se destacar os seguintes:

Custos Fixos: Custo fixo total (CFT) - compreende os valores que não sofrem alteração, independentemente da quantidade produzida (q), à medida que o custo fixo médio $(\mathrm{CFMe})$ é proporcionalmente contrário à produção. Assim, à medida que se aumenta a quantidade de animais produzidos, o total de custos não se altera, mesmo existindo diluição desse valor ao longo da produção. O principal custo fixo identificado no criatório de pacas é a depreciação das instalações.

$$
C F M e=\frac{C F T}{q}
$$

Custos Variáveis: Custo variável total (CVT) compreende os valores que sofrem variações, de acordo com a quantidade produzida (q). O custo variável médio (CVMe) representa a soma do custo variável total e a quantidade produzida. Dentre custos variáveis, listam-se os gastos com a identificação dos animais.

$$
C V M e=\frac{C V T}{q}
$$

Custo do Capital: Corresponde a quanto o investidor deixa de receber ao investir seu dinheiro na criação de pacas. A taxa aplicada na análise para o cálculo de custo do capital empregado é de $6 \%$ ao ano, usualmente empregada nos investimentos privados e equivalente ao rendimento da caderneta de poupança em 2015.

Valor Presente Líquido: Corresponde aos custos de oportunidade do capital. O investimento na criação depacas só pode ser considerado viável seo seu valor líquido presente for considerado positivo.

Relação Custo-Benefício: Corresponde ao quantitativo de entrada de recursos no caixa menos o valor investido anualmente.

\section{Resultados e Discussão}

O plantel analisado correspondeu a 36 matrizes e 12 reprodutores, gerando um plantel estabilizado quando alcançar um número médio de 59 animais, prontos para serem comercializados a partir do quinto ano, considerando-se que os indivíduos são capturados da fauna local ou recebidos pelo IBAMA, depois de sofrerem maus tratos, tráfico ou de doações, os mesmos não se apresentam adaptados ao novo ambiente (cativeiro) (LOURENCO; DIAS; GOMES, 2008) (Tabela 1).

Tabela 1: Desenvolvimento e Estabilização do Plantel no período de cinco anos.

\begin{tabular}{lccccccc}
\hline \multicolumn{1}{c}{ Discriminação } & Ano (0) & $\mathbf{( 1 )}$ & $\mathbf{( 2 )}$ & $\mathbf{( 3 )}$ & $\mathbf{( 4 )}$ & (5) & Plantel estabilizado \\
\hline Reprodutores & 12 & 12 & 12 & 12 & 12 & 12 & 12 \\
Matrizes & 36 & 36 & 36 & 36 & 36 & 36 & 36 \\
Crias & 28 & 36 & 43 & 54 & 57 & 57 & 275 \\
Natalidade (10\%) & 3 & 3 & 4 & 5 & 6 & 6 & 27 \\
Mortalidade (5\%) & 1 & 2 & 2 & 2 & 3 & 3 & 13 \\
Total de Animais & 72 & 79 & 85 & 95 & 96 & 96 & 98 \\
Compras & 0 & 0 & 0 & 0 & 0 & 0 & 0 \\
Total de vendas & 0 & 20 & 26 & 36 & 37 & 37 & 59 \\
\hline
\end{tabular}

A Tabela 1 está baseada em uma taxa de prenhez de $40 \%$ no primeiro ano, $50 \%$ no segundo ano, $60 \%$ no terceiro ano, $75 \%$ no quarto ano, $80 \%$ no quinto ano, período em que alcança estabilização do plantel e, a partir, tem-se uma taxa de prenhez $85 \%$ ao ano, uma taxa de mortalidade de $5 \%$ e uma taxa de natalidade de $10 \%$. O Intervalo considerado entre partos é de seis meses, o que corresponde a dois partos por ano, sendo que o tamanho da prole é de uma cria por parto (LOURENCO; DIAS; GOMES, 2008).

As vendas das pacas podem ser iniciadas a partir do primeiro ano,sendo possível estimar a receita proveniente de sua comercialização, por meio do preço unitário de venda. A média de preço em junho de 2015 foi de U\$\$11,29/Kg, com o animal atingindo o peso médio de seis quilos, rendendo a média de U\$\$ 67,74 por carcaça, valores estes pagos em Rio Branco, AC, preço bem inferior ao que é praticado nas capitais Belo Horizonte, São Paulo e Rio de Janeiro, nas quais variam de U\$\$ 19,35 a 29,03/Kg (LOURENCO; DIAS; GO-
MES, 2008).

Na Tabela 2, observa-se que há uma tendência crescente de receita, verificada entre os anos zero e cinco, quando o plantel da criação de paca se estabiliza. Isto ocorre como consequência direta do número de animais nascidos e comercializados. 
Tabela 2: Evolução das Receitas com a Comercialização das pacas (U\$ \$ 3,10)

\begin{tabular}{lcccccc}
\hline Discriminação & Ano (0) & Ano (1) & Ano (2) & Ano (3) & Ano (4) & Ano (5) \\
\hline Vendas & 0 & 20 & 26 & 36 & 37 & 37 \\
Receita & 0 & $1.354,83$ & $1.761,29$ & $2.438,70$ & $2.506,45$ & $2.506,45$ \\
\hline
\end{tabular}

A Tabela 3 apresenta os dados de receitas com a comercialização da porção individual de carne de paca nos restaurantes.

Tabela 3: Receitas com a comercialização da porção individual (250g) de carne de paca nos restaurantes de Rio Branco (U\$\$ $3,10)$

\begin{tabular}{lccc}
\hline Discriminação da porção individual (U\$) & 9,67 & 12,90 & 16,12 \\
\hline Lucratividade por kg (U\$\$) & 27,41 & 40,32 & 53,22 \\
Lucratividade (\%) & $71 \%$ & $78 \%$ & $82,5 \%$ \\
\hline
\end{tabular}

Para a construção do galpão com largura de $9 \mathrm{~m} \times 18 \mathrm{~m}$ de comprimento, dividida em 12 baias de $12 \mathrm{~m}^{2}$, medida considerada adequada para criação de 48 animais, distribuídos em três fêmeas e um macho por baia, levou-se em consideração todos os insumos ofertados na propriedade, principalmente, a extração da madeira, feita por um operador de motosserra profissional, em que se faz o beneficiamento desse material (tábuas, peças, mourões etc.) para a constru- ção, diminuindo, assim, o capital de investimento da obra.

Quanto aos insumos a serem adquiridos em lojas de materiais de construção, tais como: cimento, telha, areia, dobradiça, prego, brita, chapa de zinco, tijolos e tela; também foram feitos levantamentos conforme pesquisas de mercado local. Na Tabela 4, pode-se observar a média dos valores dos materiais a serem utilizados na construção do galpão.

Tabela 4 - Valor médio dos materiais utilizados na construção do galpão (cotação de junho de 2015/ U\$\$ 3,10)

\begin{tabular}{lccc}
\hline \multicolumn{1}{c}{ Descrição } & Unidade & Valor Médio Unidade & Valor \\
\hline Cimento & 10 sacas & 10,34 & 103,40 \\
Telha & $66 u n d$ & 4,28 & 282,48 \\
Areia & $5 \mathrm{~m}$ & 79,35 & 396,75 \\
Dobradiças & $22 \mathrm{und}$ & 5,69 & 125,18 \\
Prego & $10 \mathrm{Kg}$ & 2,47 & 24,70 \\
Tijolo & 1 milheiro & 217,74 & 217,74 \\
Tela 1m 1/2 & $142 \mathrm{~m}$ & 2,51 & 356,42 \\
Brita & $2 \mathrm{~m}$ & 93,00 & 186,00 \\
Chapa de Zinco 1,5m & $78 \mathrm{~m}$ & 16,07 & $1.253,46$ \\
Operador de motosserra & 1 & 290,32 & 290,32 \\
Total & & & $3.236,45$ \\
\hline
\end{tabular}

Quanto aos investimentos anuais para manejo do plantel (brinco de identificação, materiais de limpeza, conjunto de EPI e equipamentos) não foram consideradas variações de preços no decorrer dos cinco anos até a estabilização do plantel, por motivos de não haver estimativas de inflação para esses insumos. Abaixo, seguem as tabelas referentes aos investimentos e custos ao ano, na construção e manutenção do criatório (investimentos e gastos ano zero (Tabela 5), custos para o ano zero (Tabela 6), custos para o ano um (Tabela 7), custos para o ano dois (Tabela 8), custos para o ano três (Tabela 9), custos para o ano quatro (Tabela 10), custos para o ano cinco (Tabela 11).

Tabela 5: Discriminação dos Investimentos e Gastos no Ano zero (U\$\$ 3,10)

\begin{tabular}{lcc}
\hline Discriminação & Valor & Acumulado \\
\hline Galpão & $3.236,45$ & $3.236,45$ \\
Mão de obra & $3.145,16$ & $3.145,16$ \\
Remuneração de capital - 6\% & & $\mathbf{6 . 3 8 1 , 6 1}$ \\
\hline
\end{tabular}

No ano zero tem-se um investimento de U\$\$ 6.381,61 devido à necessidade de contratação de mão de obra especializa, carpinteiros, pedreiros e operador de motoserra, bem como a aquisição de insumos não disponíveis na propriedade como ferragens e materiais de contrução,o que ocasionou a elevação dos valores. 
Tabela 6: Estimativa dos custos para manutenção do plantel no ano zero (U\$ \$ 3,10)

\begin{tabular}{|c|c|c|c|c|}
\hline Discriminação & Unidade & Quantidade & Valor & Total \\
\hline Custo Operacional Efetivo & & & & $1.077,85$ \\
\hline Mão de obra para manejo & & & & 744,60 \\
\hline Familiar & Horas & 730 & 1,02 & 744,60 \\
\hline Medicamentos/Assistência & - & - & - & $*$ \\
\hline Alimentação & - & - & - & $* *$ \\
\hline Brincos de identificação & Und & 72 & 1,01 & 72,72 \\
\hline Materiais de limpeza & Und & 24 & 4,72 & 113,28 \\
\hline Conjunto de EPI & Und & 3 & 10,20 & 30,60 \\
\hline Equipamentos & Und & 6 & 8,69 & 52,14 \\
\hline Transporte dos animais & - & - & - & - \\
\hline Taxa anual do Ibama & Und & 1 & 64,51 & 64,51 \\
\hline Custo operacional total & & & & $1.120,96$ \\
\hline Custo operacional efetivo & & & & $1.077,85$ \\
\hline Depreciação do galpão & $\%$ & 4 & $1.077,85$ & 43,11 \\
\hline Custo total & & & & $1.188,21$ \\
\hline Custo Operacional Total & & & & $1.120,96$ \\
\hline Remuneração de capital & $\%$ & 6 & $1.120,96$ & 67,25 \\
\hline Custo total & & & & $1.188,21$ \\
\hline
\end{tabular}

O custo de manutenção inicial para criação de pacas equipamentos para higienização do criatório e conjuntos de C. paca, é estabelecido em U\$ 1.188,21. Este valor deve-se materiais de segurança individual EPI, já nos anos seguintes ao fato de que, inicialmente, faz-se necessária a identificação estes valores tendem a diminuir, como é o caso apresentado de todos os 72 animais, aquisição de material de limpeza, na Tabela 7.

Tabela 7: Estimativa dos custos para manutenção do plantel no ano 1(U\$\$ 3,10)

\begin{tabular}{|c|c|c|c|c|}
\hline Discriminação & Unidade & Quantidade & Valor & Total \\
\hline Custo Operacional Efetivo & & & & 958,75 \\
\hline Mão de obra para manejo & & & & 744,60 \\
\hline Familiar & Horas & 730 & 1,02 & 744,60 \\
\hline Medicamentos/Assistência & - & - & - & $*$ \\
\hline Alimentação & - & - & - & $* *$ \\
\hline Brincos de identificação & Und & 36 & 1,01 & 36,36 \\
\hline Materiais de limpeza & Und & 24 & 4,72 & 113,28 \\
\hline Conjunto de EPIs & - & - & - & - \\
\hline Equipamentos & - & - & - & - \\
\hline Transporte dos animais & - & - & - & - \\
\hline Taxa anual do Ibama & Und & 1 & 64,51 & 64,51 \\
\hline Custo operacional total & & & & 997,10 \\
\hline Custo operacional efetivo & & & & 958,75 \\
\hline Depreciação do galpão & $\%$ & 4 & 958,75 & 38,35 \\
\hline Custo total & & & & $1.056,92$ \\
\hline Custo Operacional Total & & & & 997,10 \\
\hline Remuneração de capital & $\%$ & 6 & 997,10 & 59,82 \\
\hline Custo total & & & & $1.056,92$ \\
\hline
\end{tabular}


Os gastos na manutenção para o primeiro ano estão em U\$ 1.056,92, valor este inferior ao do ano zero, o que se deve ao fato de não haver gastos com a identificação dos animais adultos, aquisição de EPIs e equipamentos para higienização do criatório.

Tabela 8: Estimativa dos custos para manutenção do plantel no anodois (U\$ $\$ 3,10$ )

\begin{tabular}{lcccc}
\hline \multicolumn{1}{c}{ Discriminação } & Unidade & Quantidade & Valor & Total \\
\hline Custo Operacional Efetivo & & & & $1.048,56$ \\
Mão de obra para manejo & & & & 744,60 \\
Familiar & Horas & 730 & 1,02 & 744,60 \\
Medicamentos/Assistência & - & - & - & $*$ \\
Alimentação & - & - & - & $* *$ \\
Brincos de identificação & Und & 43 & 1,01 & 43,43 \\
Materiais de limpeza & Und & 24 & 4,72 & 113,28 \\
Conjunto de EPI & Und & 3 & 10,20 & 30,60 \\
Equipamentos & Und & 6 & 8,69 & 52,14 \\
Transporte dos animais & - & - & - & - \\
Taxa anual do Ibama & Und & 1 & 64,51 & 64,51 \\
Custo operacional total & & & & $1.090,50$ \\
Custo operacional efetivo & $\%$ & 4 & $1.048,56$ & 41,94 \\
Depreciação do galpão & & & & $1.155,93$ \\
Custo total & & 6 & $1.090,50$ & $1.090,50$ \\
Custo Operacional Total & & & 65,43 \\
Remuneração de capital & & & & $1.155,93$ \\
Custo total & & & & \\
\hline
\end{tabular}

Os custos de manutenção para o segundo ano é de U\$ $\$ 1.155,93$, havendo um aumento comparado ao ano ante- rior, isso deve-se à necessidade de aquisição de EPIs e equipamentos para higienização do criatório.

Tabela 9: Estimativa dos custos para manutenção do plantel no ano três (U\$\$)

\begin{tabular}{|c|c|c|c|c|}
\hline Discriminação & Unidade & Quantidade & Valor & Total \\
\hline Custo Operacional Efetivo & & & & 976,93 \\
\hline Mão de obra para manejo & & & & 744,60 \\
\hline Familiar & Horas & 730 & 1,02 & 744,60 \\
\hline $\begin{array}{l}\text { Medicamentos/Assistên- } \\
\text { cia }\end{array}$ & - & - & - & $*$ \\
\hline Alimentação & - & - & - & $* *$ \\
\hline Brincos de identificação & Und & 54 & 1,01 & 54,54 \\
\hline Materiais de limpeza & Und & 24 & 4,72 & 113,28 \\
\hline Conjunto de EPI & - & - & - & - \\
\hline Equipamentos & - & - & - & - \\
\hline Transporte dos animais & - & - & - & - \\
\hline Taxa anual do Ibama & Und & 1 & 64,51 & 64,51 \\
\hline Custo operacional total & & & & 1.016 \\
\hline Custo operacional efetivo & & & & 976,93 \\
\hline Depreciação do galpão & $\%$ & 4 & 976,93 & 39,07 \\
\hline Custo total & & & & $1.076,96$ \\
\hline Custo Operacional Total & & & & 1.016 \\
\hline Remuneração de capital & $\%$ & 6 & 1.016 & 60,96 \\
\hline Custo total & & & & $1.076,96$ \\
\hline
\end{tabular}


No terceiro ano, a taxa de reprodução está em $60 \%$, o que garante mais animais a serem identificados, no entanto, não há aquisição de equipamentos para higienização do criatório e EPIs, fazendo com que os custos estejam avaliados em U\$ 1.076,96 inferior ao ano anterior.
No quarto ano, o plantel tem uma taxa de reprodução de $75 \%$, elevando-se assim os gastos com a identificação dos animais, bem como aquisição de equipamentos para higienização do criatório e EPIs, elevando o valor de manutenção para U\$\$1.171,51 valor superior ao ano anterior.

Tabela 10: Estimativa dos custos para manutenção do plantel no ano quatro (U\$\$ 3,10)

\begin{tabular}{lcccc}
\hline \multicolumn{1}{c}{ Discriminação } & Unidade & Quantidade & Valor & Total \\
\hline Custo Operacional Efetivo & & & & $1.062,70$ \\
Mão de obra para manejo & & & & 744,60 \\
Familiar & Horas & 730 & 1,02 & 744,60 \\
Medicamentos/Assistência & - & - & - & $*$ \\
Alimentação & - & - & - & $* *$ \\
Brincos de identificação & Und & 57 & 1,01 & 57,57 \\
Materiais de limpeza & Und & 24 & 4,72 & 113,28 \\
Conjunto de EPIs & Und & 3 & 10,20 & 30,60 \\
Equipamentos & Und & 6 & 8,69 & 52,14 \\
Transporte dos animais & - & - & - & - \\
Taxa anual do Ibama & Und & 1 & 64,51 & 64,51 \\
Custo operacional total & & & & $1.105,20$ \\
Custo operacional efetivo & & & $1.062,70$ & $1.062,70$ \\
Depreciação do galpão & $\%$ & 4 & & 42,50 \\
Custo total & & & $1.105,20$ & $1.171,51$ \\
Custo Operacional Total & & 6 & & 66,31 \\
Remuneração de capital & $\%$ & & & $1.171,51$ \\
Custo total & & & &
\end{tabular}

Tabela 11: Estimativa dos custos para manutenção do plantel no ano cinco (U\$\$)

\begin{tabular}{|c|c|c|c|c|}
\hline Discriminação & Unidade & Quantidade & Valor & Total \\
\hline Custo Operacional Efetivo & & & & 979,96 \\
\hline Mão de obra para manejo & & & & 744,60 \\
\hline Familiar & Horas & 730 & 1,02 & 744,60 \\
\hline Medicamentos/Assistência & - & - & - & $*$ \\
\hline Alimentação & - & - & - & $* *$ \\
\hline Brincos de identificação & Und & 57 & 1,01 & 57,57 \\
\hline Materiais de limpeza & Und & 24 & 4,72 & 113,28 \\
\hline Conjunto de EPIs & - & - & - & - \\
\hline Equipamentos & - & - & - & - \\
\hline Transporte dos animais & - & - & - & - \\
\hline Taxa anual do Ibama & Und & 1 & 64,51 & 64,51 \\
\hline Custo operacional total & & & & $1.019,15$ \\
\hline Custo operacional efetivo & & & & 979,96 \\
\hline Depreciação do galpão & $\%$ & 4 & 979,96 & 39,19 \\
\hline Custo total & & & & $1.080,29$ \\
\hline Custo Operacional Total & & & & $1.019,15$ \\
\hline Remuneração de capital & $\%$ & 6 & $1.019,15$ & 61,14 \\
\hline Custo total & & & & $1.080,29$ \\
\hline
\end{tabular}


No quinto ano, o plantel apresenta uma taxa de reprodução de $80 \%$, alcançando a estabilidade ao atingir $85 \%$ de reprodução ao ano, esses níveis de reprodução aumentam o número de animais a serem identificados, elevando-se, assim, os gastos que, mesmo não adquirindo equipamentos para higienização do criatório, nem EPIs, o custo com a manutenção do plantel chega U\$ 1.080,20.
Deve-se ressaltar que o galpão de criação dos animais sofre uma depreciação anual de $4 \%$ e vida útil de 20 anos, valores adicionados aos custos de manutenção do criatório, além de haver uma remuneração de capital de $6 \%$, já incluída no custo efetivo de manutenção. Ao fim dessas análises verificou-se, os indicadores de viabilidade do criatório do ano zero ao ano cinco, descrito a seguir, na Tabela 12.

Tabela 12: Indicadores de viabilidade do criatório de pacas (em U\$\$3,10)

\begin{tabular}{llllllc}
\hline \multicolumn{1}{c}{ Discriminação } & \multicolumn{1}{c}{ Ano (0) } & \multicolumn{1}{c}{ Ano (1) } & \multicolumn{1}{c}{ Ano (2) } & \multicolumn{1}{c}{ Ano (3) } & \multicolumn{1}{c}{ Ano (4) } & Ano (5) \\
\hline Custo total anual & $1.149,16$ & 895,26 & $1.101,03$ & $1.022,05$ & $1.053,46$ & $1.025,40$ \\
Vendade animais & 0 & $1.354,83$ & $1.761,29$ & $2.438,70$ & $2.506,45$ & $2.506,45$ \\
Lucro líquido anual & 0 & 459,57 & 660,25 & $1.416,65$ & $1.452,99$ & $1.481,35$ \\
\hline
\end{tabular}

Ao fazer a análise do capital investido, observa-se que o maior investimento se refere à construção das instalações (galpão) para confinamento dos animais, representando cerca de $85,5 \%$ do capital investido. Os demais custos estão relacionados ao manejo dos animais, no decorrer de toda a atividade, com pequenas variações. Nota-se também que há diferença nos custos de manutenção anual, pois os equipamentos para higienização do criatório e EPIs são substituídos a cada dois anos, já que ambos possuem vida útil de dois anos, o que ocasiona diferença nos valores. Outra diferenciação está relacionada aos gastos com a identificação dos animais que, no primeiro ano (ano 0), foram utilizados 72 brincos de identificação; nos anos seguintes diminuiu a quantidade,uma vez que só serão utilizados nas crias.

Alimentação, medicamentos, assistência veterinária e aquisição dos animais não foram considerados como gastos adicionais, já que os animais são fornecidos pelo IBAMA, por meio de doações e/ou capturados na propriedade;a assistência veterinária é fornecida por órgãos governamentais. Quanto à mão de obra, é realizada pelos proprietários, que se encarregam da manutenção dos animais. Nesse caso, foi calculado valor unitário da hora trabalhada e total de horas investidas no manejo, uma vez que o manejo diário de pacas se resume ao fornecimento de alimentos, água e medicamentos, limpeza de comedouros, bebedouros e instalações, representando cerca de duas horas de trabalho por dia. Diante disso, o valor total de horas trabalhadas podem ser consideradas como lucro para o produtor.

A alimentação dos animais foi determinada com base numa dieta balanceada com frutas, verduras, legumes, raízes e outros alimentos produzidos na propriedade e em seu entorno, o que representa significativa redução nos custos de produção, sem comprometer a nutrição e o desenvolvimento dos animais.

A partir dos custos anuais considerados para a atividade, é possível estimar o montante de investimentos e gastos do empreendimento até alcançar a estabilidade do plantel. A análise foi realizada buscando-se somente a viabilidade econômica e financeira, não sendo considerados os benefícios ambientais provenientes da atividade.

Os níveis de desempenho zootécnicos e econômicos são em parte devido ao meio em que os animais estão submetidos, os quais assemelham-se ao seu habitat natural, reduzindo assim o estresse da adaptação e traduzindo-se em potencial de produção e reprodução, pois um ambiente estressante pode gerar várias respostas negativas, dependen- do apenas da capacidade do animal de adaptar-se (BAETA; SOUZA, 1997).

Além de ser uma fonte econômica viável é, sobretudo, uma forma de preservação das espécies, mediante a conservação dos habitats naturais e porcentagem de reposição obrigatória por parte dos criadores (ROCHA, 2001).

\section{Conclusão}

A criação comercial de pacas (Cuniculus paca) pode ser uma alternativa viável de diversificação de produção e renda para os produtores rurais, no que se refere ao retorno do capital investido, com poucas horas de trabalho destinadas aos cuidados do plantel. Já para os proprietários de restaurantes é recomendável pela alta lucratividade obtida com a comercialização do produto, abrangendo também os benefícios ao meio ambiente, em decorrência do manejo destes animais.

É importante destacar ainda que o estudo em questão enfoca benefícios ambientais, no entanto, considerou-se apenas valores de uso direto, excluindo-se os indiretos, como a preservação da fauna brasileira, a diminuição da caça e do tráfico, a competição com essas atividades ilícitas e a garantia de uso futuro (pelas gerações posteriores) do bem ambiental preservado,mediante o baixo custo de aquisição da carne de paca pelos restaurantes locais e a facilidade de consumo pela população, já que é vista como uma iguaria, não só pelos acreanos, como também pela população amazônica e em outras localidades do país.

\section{Referências}

BAETA, F. C.; SOUZA, C. F. Ambiência em Edificações

Rurais. Conforto Animal. 1a edição. 246p. UFV, 1997.

CAMPO-ROZO, C.; ULLOA, A. Perspectivas y tendencias en torno al manejo de fauna participativo en América Latina.p. 27-50, 2003.

HOSKeN, F. M.; SILVEIRA, A. C. Criação de Paca. Viçosa: Aprenda Fácil, p. 262, 2001.

HOSKEN, M. F. Criação comercial de pacas. Viçosa, Minas Gerais: Manual Técnico, p. 54, 1998.

IBAMA - MINISTÉRIO DO MEIO AMBIENTE, DOS 
RECURSOS HÍDRICOS E DA AMAZÔNIA LEGAL; MMA-INSTITUTO BRASILEIRO DO MEIO AMBIENTE E DOS RECURSOS NATURAIS RENOVÁVEIS. Portaria no 118-N / 97, de 15 de outubro de 1997- criadouros comerciais da fauna silvestre brasileira. Disponível em: $<$ www.ibama.gov.br/cartas.../77-legislacao_fauna $>$. Acesso em: 28 jun. de 2015 .

LOURENCO, R. F. S.; DIAS, R. S.; GOMES, A. P. A. Criação de paca (Agouti paca) como alternativa de diversificação de produção e renda em Minas Gerais. In: CONGRESSO DA SOCIEDADE BRASILEIRA DE ECONOMIA, ADMINISTRAÇÃO E SOCIOLOGIA RURAL, 2008, Rio Branco, AC. Anais... p.1-20. (Resumo), 2008.

LUI, J. F.; NETO, A. C. Conservação e uso de animais silvestres. In: SEVERINO GONZAGA NETO. Anais do XVIII Congresso Brasileiro de Zootecnia e X Congresso Internacional de Zootecnia. 10 ed. João Pessoa PB: Zootec, v. 18, p. 1-10, 2008.

MIRANDA, R. J. S. et al. Viabilidade econômica da criação de caititus (Tayassutajacu): Um estudo de caso. In: CONGRESSO DA SOCIEDADE BRASILEIRA DE ECONOMIA, ADMINISTRAÇÃO E SOCIOLOGIA RURAL, 48., 2010, Campo Grande, Brasil. Anais... Campo Grande: SOBER, Disponível em: < http://www.sober.org.br/ palestra/15/720.pdf $>$. Acesso em: 03 jul. 2015.

MOREIRA, J. R.; MACDONALD, D. W. Técnicas de manejo de capivaras e outros grandes roedores na Amazônia, p. 186-213,1997. In: VALLADES-PÁDUA, C.; BODMER, R. E.; WELLEN, J. L. Manejo e Conservação de Vida Silvestre no Brasil. Sociedade Civil Mamirauá, Belém, Pará.

NOGUEIRA-FILHO, S. L. G.; NOGUEIRA, S. S. C. Criação comercial de animais silvestres: Produção e comercialização da carne e subprodutos na região sudeste do Brasil. Revista Econômica do Nordeste, v. 31, n. 2, p. $188-195,2000$

NOGUEIRA-FILHO, S. L. G.; NOGUEIRA, S. S. Criação de Pacas (Agouti paca). Piracicaba: FEALQ, p. 60,1999.

PEREIRA, T. G.; NORONHA, C. M. S.; VARGAS, E. T. Monitoramento do comportamento reprodutivo e territorialista de capivaras (Hydrochoerushydrochaeris) no IFMG-Campus Bambuí. In: I Mostra de Extensão do IFMG - Campus Bambuí, 2014.

PÉREZ, E.M. MammalianSpecies - Agouti paca. The American society of Mammalogists. n. 404, p. 1-7, 1992.

RIBEIRO, V. M. F.; ZAMORA, L. M. Pacas e capivaras criação em cativeiro com ambientação natural. Rio Branco-AC: Bagaço, p. 48, 2008.

ROCHA D. C.C.; CARDOZO, R. M. Desenvolvimento estratégico na criação e manejo de animais silvestres em
Guarapuava-PR., - In: ZOOTEC 2001. 09 a 11 de maio de 2001. Goiânia-GO.

SMYTHE, N. Steps toward domesticating the paca $($ Agouti $=$ Cuniculus paca $)$ and prospects for the future. In: ROBINSON, J. G.; REDFORD, K. H. Neotropical wildlife use and conservation. University of Chicago Press, Chicago, USA. p. 202-216, 1991.

STRADIOTTI, C. G. P. et al. Estudo hematológico de pacas (Agouti paca, L.1766) sob condições de cativeiro. XII Encontro Latino Americano de Iniciação Científica e VIII Encontro Latino Americano de Pós-graduaçãoUniversidade do Vale do Paraíba,2007. Disponível em: $<$ http://www.inicepg.univap.br/cd/INIC_2008/anais/ arquivosEPG/EPG01236_01_O.pdf $>$.Acesso em: 28 jun. de 2015.

ZUCARATTO, R.; CARRARA, R.; FRANCO, B. K. S. Dieta da paca (Cuniculus paca) usando métodos indiretos numa área de cultura agrícola na Floresta Atlântica brasileira. Biotemas (UFSC), v. 23, p. 235-239, 2010.

Recebido em: 12.01 .2016 Aceito em: 01.06.2016 